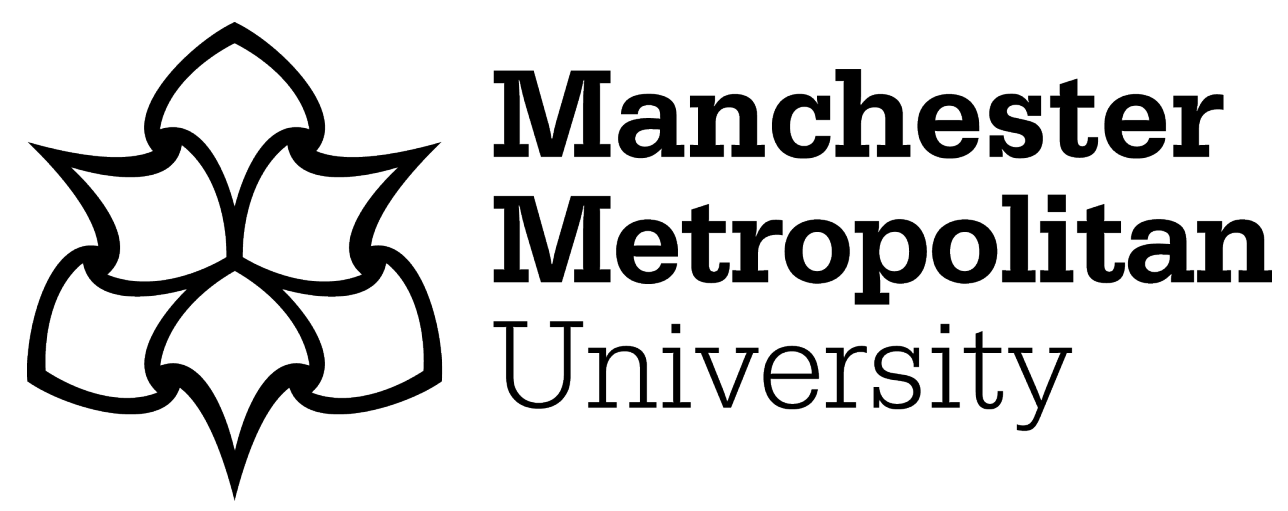

Jones, P, Klapper, R ORCID logoORCID: https://orcid.org/0000-0002-16807752, Ratten, $V$ and Fayolle, A (2018) Emerging themes in entrepreneurial behaviours, identities and contexts. International Journal of Entrepreneurship and Innovation, 19 (4). pp. 233-236. ISSN 1465-7503

Downloaded from: https://e-space.mmu.ac.uk/625015/

Version: Accepted Version

Publisher: SAGE Publications Inc.

DOI: https://doi.org/10.1177/1465750318772811

Please cite the published version 
Emerging themes in entrepreneurial behaviours, identities and contexts

Paul Jones, Rita Klapper, Vanessa Ratten, Alain Fayolle. The International Journal of Entrepreneurship and Innovation, vol. 19, 4: pp. 233-236. , First Published April 26, 2018.

\section{Emerging themes in entrepreneurial behaviours, identities and contexts}

Keywords

behaviour, context, entrepreneurial, identity, themes

\section{Introduction}

Entrepreneurship research needs to be open to novel research methods, theories and questions (Shepherd, 2015). Thus, entrepreneurship research needs to be progressive in terms of methodological approaches and providing innovative insights (McCaffrey, 2017). This special issue (SI) focuses on advancing the entrepreneurship literature by enhancing understanding of the connections between entrepreneurial behaviours, identities and contexts. To achieve this, we seek to highlight how the emerging themes from the

\section{Role of entrepreneurial behaviour, identities and context}

Entrepreneurial behaviour has been traditionally embedded within certain contexts that are characterized by dynamism

Corresponding author:

Paul Jones, International Centre for Transformational Entrepreneurship, Coventry University, Coventry, West Midlands, CV1 5FB, UK. Emails: ac0359@coventry.ac.uk; Paul.Jones@coventry.ac.uk entrepreneurship literature can be addressed by analysing the role of behaviour, context and identity. Therefore, this article proposes that each of these connections can either increase or decrease the level of entrepreneurship in society to bring about transformational change. The research questions that this SI addresses are

the following: (1) What kind of emerging contexts are influencing entrepreneurial behaviour? and (2) What can we learn from emerging themes about entrepreneurial identities?

Answering these questions is important. Despite the popularity of entrepreneurship, there is still lack of integration with the literature on entrepreneurial behaviour, contexts and identity. To do this, the article is structured as follows. First, a brief overview of entrepreneurial behaviours, context and identity is stated. Next, the articles in the special journal issue are discussed. This is followed by future research gaps, policy implications and suggestions for entrepreneurs.
(Morrison, 2006). This has changed with the realization that the context is also influenced by the identity of the entrepreneur (Drakopoulou-Dodd et al., 2016). The entrepreneurial identity is a result of the context that provides a sense of meaning and identity as a business person (Jones et al., 2017). Individuals who engage in entrepreneurial behaviour usually have specific personality traits such as being opportunity seeking, take initiative and make intuitive decisions (Gibb, 2002). Thus, it is suggested that there are emerging themes in the literature about entrepreneurial behaviours that need to be further analysed from different contexts such as emerging economies and industries that have been less favoured in the existing literature (Anggadwita et al., 2017; McElwee and Wood, 2017). This is due to most of the theories on entrepreneurial behaviours coming from a Western and developed country perspective that views the identity of entrepreneurs in a certain way (Baughn and Neupert, 2003).

Entrepreneurial behaviour can be learned and developed through educational programmes that focus on ways to foresee opportunity by engaging in proactive causes of action. Entrepreneurship education is important in providing knowledge about market and international contexts (Pickernell et al., 2013). Increasingly, entrepreneurship education is being used in a variety of contexts to enable an improved ecosystem to develop in communities (Ferreira et al., 2018; Packham et al., 2010). These entrepreneurial ecosystems facilitate a context that encourages teaching a 
Emerging themes in entrepreneurial behaviours, identities and contexts

Paul Jones, Rita Klapper, Vanessa Ratten, Alain Fayolle. The International Journal of Entrepreneurship and Innovation, vol. 19, 4: pp. 233-236. , First Published April 26, 2018.

mindset and skill set that is open to change (Jones and Jones, 2014).

The process of entrepreneurship involves entrepreneurs interacting with their environment to seize opportunities (Ratten, 2014). Morrison (2006) suggests that there are positive and negative entrepreneurial cues that can be differentiated based on social, economic and psychological outcomes. Social outcomes refer to creating a conducive culture for entrepreneurship based on social networks and cooperation. However, there can be negative social effects such as discrimination based on gender, religion or political affiliation that creates tension in society (Palalic' et al., 2017). Economic outcomes include the use of emerging technology and knowledge-intensive services to create efficiencies in the marketplace (Ferreira et al., 2017a; Zivdar et al., 2017). This helps to build societal wealth through social mobility. There are also negative results from economic events, and this includes the need for people to upskill their training or change positions. Psychological effects include the enhanced sense of independence and motivation associated with entrepreneurship (Ferreira et al., 2017b). There can be too much emphasis on the need to achieve and be wealthy in society, which is reflected in entrepreneurial behaviours.

Porfirio et al. (2016) states that contexts are important for entrepreneurship as they are a characteristic of different development stages and conditions in industries. These contextual influences on entrepreneurship influence behaviour and effective action (Chetty et al., 2014). Contexts include organizational, industry and society that impacts on the cumulative behaviour of an entrepreneur (Cope, 2005). Jones et al.

Each of these contexts has economic, legal, political and social attributes that affect entrepreneurial behaviours (Maritz and Donavan, 2015). Context can help or hinder an entrepreneur depending on the circumstances. Johannisson et al. (1994) viewed contexts in a positive light as they provide the means for an entrepreneur to realize his/her business potential. However, context can present obstacles and make it challenging for businesses to gain momentum (Fletcher, 2011). Granovetter (1992) suggested that social contexts provide an important way for individuals to learn and change their behaviour. This is important for entrepreneurs who can utilize social interactions to evolve their behaviour and derive new ways of working (Gartner, 1985). The interplay between entrepreneurial behaviours, context and identity is an emerging theme in the research, which is evident in the articles in the SI. An overview of each of these articles is discussed in the next section.

\section{Overview of articles in the special issue}

The first article titled 'Identity as a causal power: Contextualising entrepreneurs concerns' by Kasperova et al. utilizes a critical realist perspective to understand entrepreneurial identity. This is helpful in understanding the way personal, material and social actions influence entrepreneurial behaviours. The study uses a sample of disabled entrepreneurs in the United Kingdom to test the theoretical framework. This helps to contribute to the literature on disadvantaged and minority entrepreneurs in terms of the entrepreneurial context.

The second article titled 'Contextualising entrepreneurial identity amongst Syrian refugees in Jordan: The emergence of a destabilized habitus' by Refai et al. focuses on how refugees become entrepreneurs because of previous adverse conditions. This subject is topical, given the current global refugee situation, and this article provides a business perspective. The way Syrian refuges in Jordan become entrepreneurs is addressed through analysing their human capital and social networks. The results contribute to the literature regarding societal entrepreneurship by addressing the alternate ways refugees interact with institutional and societal environments.

The third article titled 'Effect of legal and regulatory framework on SMEs growth in Ghana' by Nyarku and Oduro discusses the importance of African entrepreneurship in the global economy. The different entrepreneurial climate in Ghana based on bureaucracy,

policy and trade regulations is examined in terms of smallto medium-sized enterprise (SME) growth. The results of the article contribute to the literature regarding legal and regulatory factors influencing entrepreneurship in emerging economies.

The following article entitled 'Rural entrepreneurial space and identity: A study of local tour operators and 'the Nenets' Indigenous reindeer herders' by Gorbuntsova et al. discusses the link between entrepreneurship and tourism. This study increases our understanding regarding the role rural entrepreneur's play in tourism development. Tourism is context that differs from other industries due to the large number of SMEs that are engaged in entrepreneurial pursuits. Thus, this study provides a useful discussion regarding the context of indigenous reindeer herders and their interaction with tourism providers.

The fifth article titled 'The mediating role of female migration on social entrepreneurship activity' by Kickul et al. addresses the nascent literature regarding social enterprises. This is done by suggesting that there is a link 
Emerging themes in entrepreneurial behaviours, identities and contexts

Paul Jones, Rita Klapper, Vanessa Ratten, Alain Fayolle. The International Journal of Entrepreneurship and Innovation, vol. 19, 4: pp. 233-236. , First Published April 26, 2018.

with a country's governance and female migration rates in terms of the level of social entrepreneurial activity. The study stresses the need for social entrepreneurship research to focus on macro-level variables.

\section{Future research suggestions}

For researchers, the SI provides suggestions on the contexts of entrepreneurship and potential future study avenues. Moreover, our SI alerts researchers to nascent themes that will be of future importance. Researchers should consider the conflicting views on entrepreneurial behaviour and craft novel lines of research to enhance the literature. Future studies could extend the research on entrepreneurial behaviours by reconceiving our understanding of the context. The sequences of behaviour for an entrepreneur could be analysed for patterns across international contexts. This will extend the literature on contextualization of entrepreneurship by providing lessons for entrepreneurs in terms of observed actions. Entrepreneurs change their behaviours based on their perspective of a context, thus a deeper understanding of the interplay with entrepreneurial identity could enrich the literature.

To advance conceptually and theoretically the research on entrepreneurial behaviours, there needs to be increased interaction with other disciplines. Furthermore, research needs to develop the current intellectual boundaries to enhance the theorization of entrepreneurial behaviours. This will create further linkages with other disciplines such as psychology, global talent management and performance systems to develop the research regarding context, behaviour and identity. We urge scholars to pay increased attention to the emerging themes discussed here to enable further discoveries.

For policymakers, this SI offers novel ways for improved practices for managers and business owners. A key challenge for future research is to build on existing theories to derive enhanced frameworks for understand entrepreneurial behaviours, identities and context. We require increased research on the contextualization of entrepreneurship that focuses on different market and industry segments, the behaviour of the entrepreneur recognition while engaging in a continual process of learning.

For entrepreneurs, the contributions in this special journal issue will assist them refine their behaviours to be more aligned to different contexts. This article has demonstrated the benefits of viewing entrepreneurial behaviours from a more holistic perspective that takes into account societal change. The findings from the articles in the SI help to develop a more critical understanding of changes in entrepreneurial behaviours and the way context influences entrepreneurial identity.

\section{Conclusion}

This article has discussed research issues we regard that will be useful to develop in future years. While there is a strong body of knowledge on entrepreneurial behaviours, we have highlighted that there are still areas to be discovered. We view the field as becoming more interdisciplinary in its journey to have more relevant and practical findings. There is a need for more contextual research in entrepreneurship as there are inherent challenges in the global environment. While entrepreneurship research has become a mainstream business discipline, there is no need for complacency with the research on entrepreneurial behaviours. We need to improve current research by extending it to new contexts that can increase the quality of knowledge. This is a continual journey that needs a mixed-method approach to provide for improved triangulation of findings. It is apparent that new contexts will increase the depth and breadth of current research to provide novel perspectives.

\section{Declaration of conflicting interests}

The author(s) declared no potential conflicts of interest with respect to the research, authorship, and/or publication of this article.

\section{Funding}

The author(s) received no financial support for the research, authorship, and/or publication of this article.

\section{ORCID iD}

Paul Jones (D) http://orcid.org/0000-0003-0417-9143

\footnotetext{
involved and the outcomes. This article suggests that context is not discrete but rather is an evolving topic that reflects changes in the environment. Thus, context is an unfolding experience that can be exploited depending on the behaviour of an entrepreneur. This involves an entrepreneur building their identity based on opportunity
}

\section{References}

Anggadwita G, Luturlean BS, Ramadani V, et al. (2017) Sociocultural environments and emerging economy entrepreneurship: women entrepreneurs in Indonesia. Journal of Entrepreneurship in Emerging Economies 9(1): 85-96. 
Emerging themes in entrepreneurial behaviours, identities and contexts

Paul Jones, Rita Klapper, Vanessa Ratten, Alain Fayolle. The International Journal of Entrepreneurship and Innovation, vol. 19, 4: pp. 233-236. , First Published April 26, 2018.

Baughn CC and Neupert KE (2003) Culture and national conditions facilitating entrepreneurial start-ups. Journal of International Entrepreneurship 1(3): 313-330.

Chetty SK, Partanen J, Rasmussen ES, et al. (2014) Contextualising case studies in entrepreneurship: a tandem approach to conducting a longitudinal cross-country case study. International Small Business Journal 32(7): 818-829.

Cope J (2005) Toward a dynamic learning perspective of entrepreneurship. Entrepreneurship Theory and Practice 29(4): 373-397.

Drakopoulou-Dodd S, Jones P, McElwee G, et al. (2016) The price of everything, and the value of nothing? Stories of contribution in entrepreneurship research. Journal of Small Business and Enterprise Development 23(4): 918-938. Ferreira JJ, Fayolle A, Ratten V, et al. (2018) Entrepreneurial Universities: Collaboration, Education and Policies. UK: Edward Elgar.

Ferreira JJ, Fernandes CI and Ratten V (2017a) Entrepreneurship, innovation and competitiveness: What is the connection? International Journal of Business and Globalisation 18(1): 7395.

Ferreira JJ, Ratten V and Dana LP (2017b) Knowledge spilloverbased strategic entrepreneurship. International Entrepreneurship and Management Journal 13(1): 161-167.

Fletcher DE (2011) A curiosity for contexts: entrepreneurship, enactive research and autoethnography. Entrepreneurship and Regional Development 23(1-2): 65-76.

Gartner WB (1985) A conceptual framework for describing the phenomenon of new venture creation. Academy of Management Review 10(4): 696-706.

Gibb A (2002) In pursuit of a new 'enterprise' and 'entrepreneurship' paradigm for learning: creative destruction, new values, new ways of doing things and new combinations of knowledge. International Journal of Management Reviews 4(3): 233-269.

Granovetter M (1992) Economic institutions as social constructions: a framework for analysis. Acta sociologica 35(1): 3-11.

Johannisson B, Alexanderson O, Nowicki K, et al. (1994) Beyond anarchy and organization: entrepreneurs in contextual networks. Entrepreneurship \& Regional Development 6(4): 329-356.

Jones P and Jones A (2014) Attitudes of Sports Development and Sports Management undergraduate students towards entrepreneurship: a university perspective towards best practice. Educationp Training 56(8/9): 716-732.

Jones P, Jones A, Williams-Burnett N, et al. (2017) Let's get physical: stories of entrepreneurial activity from sports coaches/instructors. International Journal of Entrepreneurship and Innovation 18(4): 219-230.

Maritz A and Donovan J (2015) Entrepreneurship and innovation: setting an agenda for greater discipline contextualisation.

Educationp Training 57(1): 74-87.
McCaffrey M (2017) Extending the economic foundations of entrepreneurship research. European Management Review 15(2): 191-199.

McElwee G and Wood A (2017) Wetland entrepreneurs: diversity in diversification in Zambian farming. Journal of Small Business and Enterprise Development. Epub ahead of print 5 April 2017. DOI: 10.1108/JSBED-03-2017-0089.

Morrison A (2006) A contextualisation of entrepreneurship. International Journal of Entrepreneurial Behaviour \& Research 12(4): 192-209.

Packham G, Jones P, Miller C, et al. (2010) Attitudes towards entrepreneurship education: a comparative analysis.

Educationp Training 52(8/9): 568-586.

Palalic' R, Ramadani V, Đilovic' A, Dizdarevic' A, et al. (2017) Entrepreneurial intentions of university students: a casebased study. Journal of Enterprising Communities: People and Places in the Global Economy 11(3): 393-413.

Pickernell D, Senyard J, Jones P, et al. (2013) New and young firms: entrepreneurship policy and the role of governmentevidence from the Federation of Small Businesses survey. Journal of Small Business and Enterprise Development 20(2):

$358-382$

Porfirio JA, Carrilho T and Monico LS (2016) Entrepreneurship in different contexts in cultural and creative industries. Journal of Business Research 69(11): 5117-5123.

Ratten V (2014) Encouraging collaborative entrepreneurship in developing countries: the current challenges and a research agenda. Journal of Entrepreneurship in Emerging Economies 6(3): 298-308.

Shepherd D (2015) Party on! A call for entrepreneurship research that is more interactive, activity based, cognitively hot, compassionate and prosocial. Journal of Business Venturing 30(4):

489-507.

Zivdar M, Imanipour N, Talebi K, et al. (2017) An explorative study of inputs for entrepreneurs' decision-making to create new venture in a high-tech context. International Journal of Entrepreneurship and Innovation 18(4): 243-255. 